\title{
El viaje del alma después de la muerte. Un motivo homérico en Fuego en Casabindo de Héctor Tizón ${ }^{1}$
}

\author{
The journey of the soul after death. A Homeric motif in Fuego en Casabindo by Héctor Tizón
}

Alejandra Mabel Liñán

Universidad Nacional del Nordeste, Argentina

alejandra.linan@comunidad.unne.edu.ar

(iD https://orcid.org/0000-0002-6958-285X

\section{Resumen:}

La obra narrativa de Héctor Tizón incluye, desde su primera novela publicada, Fuego en Casabindo (1969), la adscripción a la tradición homérica, cifrada en la cita del epígrafe, de un fragmento de Odisea (11.216-224), enunciado por Anticlea, quien revela a su hijo lo que ocurre con los seres humanos cuando mueren. Al mismo tiempo, incorpora en el mundo narrado los cantares y los relatos populares tradicionales, los mitos y creencias de la región noroeste de la Argentina. La escatología es un conocimiento que articula estas culturas tan alejadas en el tiempo y el espacio.

Este artículo sostiene que el motivo griego integrado en la novela no es un componente secundario, sino que constituye la matriz narrativa, da forma a la estructura novelesca y resulta significativo para la interpretación.

Palabras ClaVe: Motivo, Escatológico, Novela, Homero, Héctor Tizón, Intertextualidad.

\section{Abstract:}

Héctor Tizón's narrative work includes, from his first novel published, Fuego en Casabindo (1969), the ascription to the Homeric tradition, encoded in the citation, as an epigraph, of a fragment of Odyssey (11,216-224), enunciated by Anticlea, who reveals to his son what happens to human beings when they die. At the same time, it incorporates into the narrated world the traditional songs and folk tales, the myths and beliefs of the northwest region of Argentina. Eschatology is one knowledge that articulates these cultures so distant in time and space.

This article maintains that the Greek motif integrated into the novels is not a secondary component. Rather, the eschatological motif establishes the narrative matrix and shapes the novel structure, while providing significant elements for the interpretation. KEYwords: Motif, Eschatological, Novel, Homer, Héctor Tizón, Intertextuality.

$\dot{\alpha} \lambda \lambda^{\prime} \alpha \tilde{\tau} \tau \eta \delta \dot{\delta} \kappa \eta \dot{\varepsilon} \sigma \tau i \beta \rho \sigma \tau \tilde{\omega} \nu, ~ o ̈ \tau \varepsilon \tau i \zeta ~ \kappa \varepsilon \theta \dot{\alpha} \nu \eta \sigma \nu^{2}$

\section{EL DIÁLOgO ENTRE LO REgIONAL Y LO UNIVERSAL}

La literatura tizoniana ${ }^{3}$ abarcó, en buena parte de su producción, temas ligados al ámbito geográfico, histórico y cultural jujeño. Sin embargo, no se privó de construir diálogos con mitos y motivos universales.

Desde las primeras a las últimas publicaciones, es notable la continuidad de su proyecto estético. A la par de la insistencia en temas tales como el arraigo y el desarraigo, el amor y la muerte, la soledad esencial y el desasimiento de la vida, el despojamiento histórico de la tierra de los pueblos autóctonos y la fortaleza de la cultura local a pesar de las aculturaciones, el tren como la posibilidad de otras vidas, los viajes y los regresos, pueden distinguirse también diferencias por los cambios de perspectivas, ambientes y estilo en su narrativa. Las novelas van transitando progresivamente desde una marcada localización en la región de pertenencia al desplazamiento y hasta borramiento de las señales de lugar y tiempo, hacia configuraciones más generalizantes y universales y a estructuras narrativas menos complejas, si se comparan con las tres primeras novelas. 
Estas novelas forman una suerte de trilogía, en la cual se propuso testimoniar la historia de Jujuy desde la segunda mitad del siglo XVIII, pasando por el éxodo jujeño (Sota de bastos, caballo de espadas, 1975) y las últimas rebeliones indígenas en la lucha por conservar la posesión de las tierras (Fuego en Casabindo, 1969), hasta los avances del progreso con la llegada del ferrocarril a la región, en contraste con las tradiciones puneñas, en las primeras décadas del siglo XX (El cantar del profeta y el bandido, 1972).

En su primera etapa como novelista, la relación con los mitos y motivos griegos toma fundamentalmente dos dimensiones. Por una parte, el montaje de diversos temas griegos, especialmente los de la epopeya homérica, se vincula con la transmisión oral de los relatos, que para este escritor es la base fundante de toda narrativa. Por otra, entre las dimensiones del mito, la escatología se torna central para analizar Fuego en Casabindo, porque permite establecer la relación de confluencia entre las creencias de los puneños y las de los antiguos griegos.

El señalamiento de la vinculación manifiesta de los mitos antiguos con los de su región de pertenencia, fundada principalmente en el oído atento a la oralidad que los liga, no implica que sea evidente en toda su obra. Pero sí puede afirmarse que, además de aquellos lugares donde la cita o la alusión la hacen ostensible, hay una latencia de la cual asoman a veces menciones, símbolos y arquetipos: Homero, Ulises y la Odisea son los más recurrentes.

Así también, con respecto a otro de los aspectos constantes de su producción literaria, la presencia del viaje y los viajeros, se puede decir que el motivo del viaje encontró su referente en la Odisea, a pesar de que la intertextualidad no se manifiesta en todas las obras.

\section{Una novela Que transcurre en la Puna}

Fuego en Casabindo narra la historia de un hombre, muerto en la batalla de Quera cuando la lucha ya había finalizado, que va en busca de su victimario para lograr que se cumpla el reencuentro ritual y morir definitivamente. La lucha de los indígenas en su última rebelión armada, que tuvo su epicentro en la Puna en los años 1874-1875, y sucesos de los años previos, conforman el contexto histórico y el ámbito geográfico y cultural de referencia.

La materia narrativa aportada por "descendientes de los que habían combatido por las tierras y fueron derrotados" (Tizón, 2000, p. 9) ha adoptado la forma de una con-fusión de voces, en una imbricación constante de la oralidad en el tejido de la escritura, evidenciada en la apropiación de discursos diversos en los que no se discrimina si son de "unos" o de "otros".

Además de la presencia de otro discurso literario materializada en la intertextualidad, como acontece con el de Homero, la narración novelesca, en su rescate de la oralidad, los amalgama también con los relatos orales de tradición andina, que aportan los discursos y saberes de los habitantes autóctonos.

La línea narrativa principal, la historia de la búsqueda del mayor por parte del tuerto, se abre en el tercer párrafo (p. 14) y se cierra al final de la novela, cuando la víctima ha logrado encontrar a su asesino y, por lo tanto, ambos han obtenido la reparación.

La formalización de esa matriz narrativa en la estructura novelesca se despliega en la fragmentación temporal y en las anacronías, es decir, se entremezcla con otros sucesos, sin señales exteriores que adviertan a los lectores.

$\mathrm{Al}$ transcribir en el exordio un pasaje de Odisea, que especialmente concierne a un conocimiento sobre el destino del alma después de la muerte, el autor no solamente sugirió el tema de la novela, sino que, de este modo, insertó su relectura en la larga tradición homérica.

\section{EL VIAJE DEL ALMA}


En Fuego en Casabindo, la cita de las palabras de Anticlea (Od. 11.216-224) como epígrafe indica desde el comienzo la centralidad que el tema escatológico adquiere en la novela. El alma del hombre muerto en la batalla de Quera se traslada por la zona, por el mundo de los vivos, en busca de su victimario, ya que sólo por medio de ese encuentro ambos podrán ser seres completos, cerrar sus trayectorias vitales, y sus almas descansarán en paz.

El pasaje citado al inicio reproduce la muy difundida versión de Luis Segalá y Estalella, en edición de Obras completas de Homero, ${ }^{5}$ Colección Clásicos inolvidables, publicada por El Ateneo (1957):

ANTICLEA: ¡Ay de mí, hijo mío, el más desgraciado de todos los hombres! No te engaña Persefonea, hija de Zeus, sino que ésta es la condición de los mortales cuando fallecen: los nervios ya no mantienen unidos la carne y los huesos, pues los consume la viva fuerza de las ardientes llamas tan pronto como la vida desampara la blanca osamenta; y el alma se va volando, como un sueño. Mas procura volver lo antes posible a la luz y llévate sabidas todas estas cosas para que luego las refieras a tu consorte (Homero, Odisea, Canto Undécimo, p. 216). ${ }^{6}$

El epígrafe de Fuego en Casabindo conecta aquella búsqueda de Odiseo para saber a fondo quién es con la búsqueda particular del muerto que, después del combate en Quera, se encamina en busca de su asesino, y que sólo completa su destino al encontrarlo.

La cita, ubicada de manera tan destacada, desde el comienzo irradia (Brunel, 1994, p. 42) sobre la novela entera y dialoga intertextualmente con saberes de la cultura puneña sobre la muerte. Desde su cosmovisión, también deben realizarse ritos propiciatorios para que el "muerto" pase definitivamente a esa condición. Víctima y victimario deben reunirse, como dos partes inseparables, sobre todo porque el asesinato del tuerto ha sido "en frío" (2000, p. 101), cuando los rebeldes indígenas ya habían sido derrotados por las fuerzas gubernamentales. Ha sido un error por enceguecimiento del victimario, un acto de hýbris, como denominaban los griegos antiguos al exceso de violencia sin sentido: "Ahora, lejos, recordaba al jinete y recordaba también su cara y el gesto al impacto de su lanza, cuando ya la batalla estaba decidida y lo que ocurría sólo era persecución, alegría de vencer, ensañamiento" (p. 101).

Así como en Homero se inicia el canto con la invocación a la musa, aquí el íncipit da el tono y adelanta la relevancia del tema escatológico en la novela.

En la prótasis épica se adelantaba el tema principal de la epopeya. Lo que se cita en el acápite de Fuego en Casabindo, lo que ocurre con el cuerpo y el alma cuando alguien muere, constituye la matriz narrativa fundamental de esta novela. Es decir que el hecho que pone en diálogo a los griegos antiguos, representadas sus creencias en el gran mito literario homérico, y a los puneños, expresadas sus creencias en el relato sobre el alma de la víctima que busca a su asesino, es la concepción del destino del alma después de la muerte que tiene elementos comunes en ambas culturas.

En Odisea habla una madre que ha muerto a causa del dolor provocado por la ausencia prolongada de su hijo. El hijo, habiendo hecho los ritos obligatorios, realiza la hazaña de entrar en contacto con el espacio sagrado de Hades -lo que le causa sufrimiento y terror-y averiguar lo que ningún ser humano puede saber en condiciones normales: qué hay más allá de lo conocido y qué ocurre con los muertos. El tópico del parlamento de la madre de Odiseo es la separación de la $\psi v \chi \eta ́$ después de la muerte.

Anticlea habla con Odiseo en el canto 11, precisamente cuando se desarrolla la nékyia, es decir, la evocación de los muertos por parte de Odiseo y el ingreso al Hades, instancia de profundización en el conocimiento de los avatares del futuro y prueba máxima que se le asigna para conocerse a sí mismo y para consagrarse como héroe. La conversación entre madre e hijo ha sido relevante para el autoconocimiento del héroe, y a la vez, para el conocimiento del mundo y del destino del alma después de la muerte.

El pasaje homérico citado en la novela remite a los saberes escatológicos de la cultura griega antigua, de diversos tiempos superpuestos, ${ }^{7}$ aunque principalmente de los comienzos de la época arcaica: la separación 
de la psyché y del cuerpo una vez realizado el rito de incineración y el posterior viaje al Hades de ese aliento

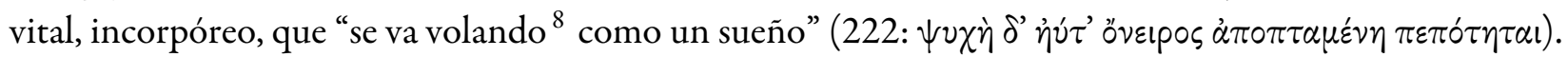

Conocemos por el mismo relato de Odiseo el caso de Elpénor $(O d .11 .51-83)$, el compañero de Odiseo que no había podido acceder definitivamente al mundo subterráneo porque no se habían realizado los debidos ritos fúnebres: su cadáver $(\sigma \tilde{\omega} \mu \alpha)$ no había sido llorado ni sepultado ( $\alpha \kappa \lambda \alpha \nu \tau o \nu$ kai $\alpha \theta \alpha \pi \tau \sigma \nu)$, por lo que su

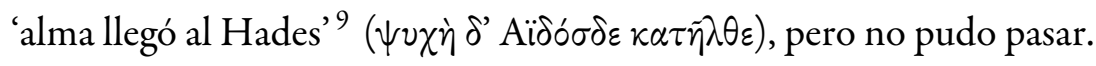

En el mundo homérico, tanto para Elpénor en Odisea como para el alma de Patroclo en Ilíada, ${ }^{10}$ cuando después de muerto se le presenta a Aquiles en un sueño para pedirle que realice las honras fúnebres (Il.XXIII. 65-107), pesa la condición de no poder dejar de andar errante, entre la vida y la muerte, hasta que se consumen los actos rituales. La advertencia de Elpénor al pedir a Odiseo que, cuando regrese al palacio de Circe, no lo deje sin llorar ni sepultar, revela que los muertos no podían permanecer fuera del Hades sin representar

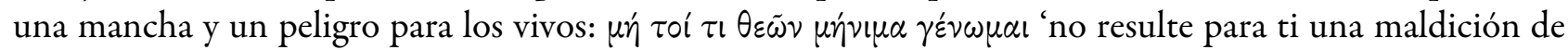
los dioses' (Od. 11.73).

Igualmente se sustenta en esta creencia el hecho de que, en Ilíada (XXIII.49-53), Aquiles pida a Agamenón que ordene la preparación de los ritos para los funerales de Patroclo con todo lo necesario para que un muerto

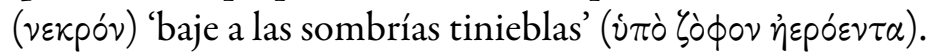

La comunicación con los muertos podía darse por medio de ritos como la nékyia, por el descenso extraordinario al Hades estando vivo, hazaña reservada a algunos héroes, o por la aparición en un sueño. En el episodio de la visita del alma de Patroclo a Aquiles en el sueño (XXIII.65-107) ambos dialogan toda la noche. A través de esa comunicación nos enteramos de que es necesario incinerar el cuerpo en una pira, a la que se agregan también ánforas de miel y aceite, cuatro caballos, dos perros tras degollarlos y doce hijos de troyanos después de matarlos con el bronce. Todo esto para que el alma separada del cadáver pueda ingresar al Hades con los honores adecuados. Al consumirse el fuego, los huesos se conservan en una urna, en esta ocasión de oro, para unirlos en el futuro con los de Aquiles. Alrededor de la pira, construyen un túmulo circular.

Estas formas de honrar a los muertos con ofrendas, sobre todo de las que fueron sus pertenencias, tienen elementos en común con las costumbres de los collas; pero en Fuego en Casabindo no se representan las de este tipo porque no se produce el entierro de los muertos, sino que finaliza con la muerte de ambos.

En las culturas andinas, no hay una división tajante entre la realidad cotidiana de los seres vivos y las presencias de los que ya fallecieron. Massei (1998, p. 75) había afirmado que, en Fuego en Casabindo, no están separados taxonómicamente el mundo de los vivos y el de los muertos, pero luego agregó la interpretación de que es el mundo de los vivos el que está muerto, con lo que trazó una analogía con el mundo de difuntos en Comala de Juan Rulfo. Desde nuestro punto de vista, la novela está impregnada de la cosmovisión de los puneños, en la que el "cielo" y el "infierno" pueden manifestarse sobre la superficie donde se desarrolla la vida.

Las tradiciones implican la creencia de que los vivos pueden interactuar con los muertos, especialmente, en sincretismo con creencias cristianas, en el día de los difuntos. Estudiosas de las culturas del noroeste argentino como Krmpotic y Vargas (2018) aclaran:

En la cosmovisión andina, la muerte implica el final de la vida física, biológica, pero no de la existencia del alma (nuna o camaquen). El alma se irá a otro mundo, y volverá cuando sea nombrada, hacia donde su cuerpo yace. Se trata de un descanso relativo, ya que el espíritu del difunto tendrá que afrontar en su nueva vida trabajos no exentos de sufrimiento: se sabe que uno sigue viviendo en el otro mundo tal como ha vivido en este. Siendo natural no es motivo de desesperación. La naturaleza es comprendida como un todo del que formamos parte y compartimos la vida (pp. 231-232).

Se vive en un orden cíclico y armónico en el que hay complementariedad e interdependencia entre todos los seres vivos y también entre las partes del mundo natural y "sobrenatural". Los ritos mortuorios tienen la función de acompañar el desprendimiento del mundo de los vivos hacia el de los muertos. Estas prácticas conllevan varias etapas para los familiares y la comunidad (pp. 232-233). Para nuestro análisis de la presencia de esta cultura en la narrativa de Tizón, tiene relevancia que los muertos no se marchan enseguida: 
El difunto llega al mundo de los muertos, en un período aproximado de un año, iniciando el viaje al décimo día después de muerto. Asimismo, el muerto debe llevar consigo todas sus pertenencias y objetos de uso personal, como ropa, herramientas, mantas, amuletos. De la misma forma, debe ir acompañado por sus despojos, como cabellos, dientes, uñas, entre otros (p. 234).

Como el alma del difunto trabaja en reciprocidad con los vivos, "el hombre andino habla con el alma cada día, está en contacto y sabe lo que quiere." Incluso recibe los mensajes "por medio de sueños, del viento o del fuego" (p. 235).

El viaje del difunto puede ser acompañado por "familiares, por un perro y por una llama para transportar sus pertenencias" (p. 235). Es responsabilidad de los familiares realizar todos los ritos de manera adecuada para que ese viaje transcurra con normalidad. En la novela, por las características del ámbito cultural de pertenencia, se registra la asociación de creencias ancestrales andinas con otras implantadas por el cristianismo desde la conquista y la evangelización; sin embargo, es dominante la cosmovisión ancestral, ${ }^{11}$ que es la que da sentido al hilo conductor de la narración.

En la Odisea, para comunicarse con las almas de los muertos, Odiseo debe darles de beber la sangre del carnero negro sacrificado para los dioses del mundo subterráneo. A pesar de que desearía abrazar a su madre cuando la ve, debe obedecer las reglas que se le han impuesto, porque no tiene dominio en el espacio sobrenatural donde ha ingresado.

Las palabras de la madre asumen la importancia de ser el vehículo de revelación de un misterio sobre la

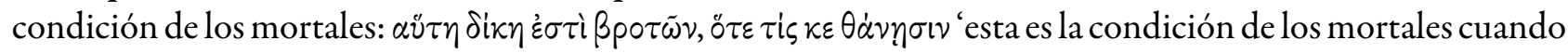
uno muere' (11.218). El poeta usa la palabra dike para indicar esta manera de ser, lo que refuerza el matiz

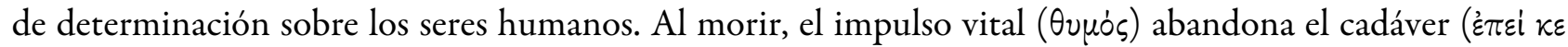

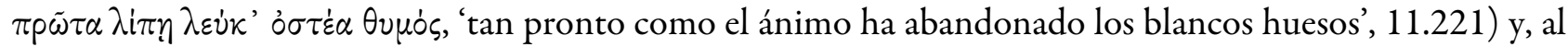

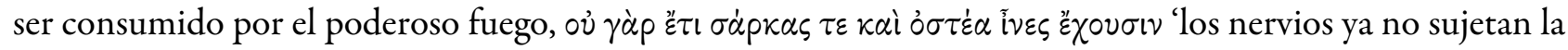
carne ni los huesos' (11.219). Así, al realizar debidamente la ceremonia fúnebre, la $\psi v \chi \eta ́$ emprende su vuelo al Hades.

Uno de los elementos comunes con las formas de vida y las costumbres ancestrales de los pueblos andinos es el condicionamiento que también obliga al tuerto, en Fuego en Casabindo, a deambular en busca de su asesino hasta que se completen los actos necesarios para que su alma pueda irse definitivamente. El caballo siente la gravedad del peso de dos hombres sobre su espinazo:

Un relámpago cruzó el horizonte; se encabritó y, perpendicular, en dos patas, de un golpe certero arrojó el exceso y comenzó a huir galopando desesperadamente. Él también sabía que debían darse prisa antes de que la carne comenzara a ceder, corrompida, y, por falta de compañía el jinete a él también se lo llevara (p. 79). ${ }^{12}$

El mayor López había matado a un hombre en frío y, a partir de allí, ambos quedaron ligados hasta su muerte. La creencia sobre el lazo indisoluble que liga a víctima y victimario se aclara cuando está muy avanzado el relato:

Sabía, como sus antepasados, que cuando alguien muere a manos de otro, víctima y victimario se confunden, se contagian el olor y los hábitos, los gestos personales, las tendencias. La víctima sigue siempre junto al victimario, de día se esconde cuando hay ruido, en el silencio reaparece, como un recuerdo en la memoria, o como un pensamiento; de noche le acompaña siempre, y en todo momento en sueños. Por el resto viven unidos hasta que el victimario muere y se libera a su vez de la cargazón del cuerpo (p. 121).

Después de aquel momento de error irremediable, buscó el cadáver, ya que podía haber una posibilidad de reconciliación de las almas antes de que el cuerpo se corrompiera, pero no lo halló al recorrer el campo de batalla "sembrado de piedras y cadáveres": "El frío y el viento absorbían el hedor que el cuerpo exhala cuando el alma huye” (p. 80). Y siguieron adelante en su búsqueda:

Pero el alma huía.

Sauzalito verde, enriédala 
Florcita de pante, pante

Caballero y caballo un largo camino por delante, y sólo poco tiempo para atraparla (pp. 80-81).

Es decir que, a lo largo de la novela, la huida del hombre muerto que ha perdido el ojo, desde el altozano donde quedan los despojos del combate, y su retorno a Casabindo, es parte de un rito que debe cumplirse para que pueda descansar en paz.

El lector se va enterando de esta condición del ser humano a través de la acción y de los comentarios del narrador, que en varias oportunidades focaliza la perspectiva desde alguno de los personajes.

El muerto merodea por el mundo de los vivos ${ }^{13}$ y actúa en él. La mayoría no lo ve, pero algunos lo perciben. Es evidente en la escena en que intenta ser escuchado por las vendedoras en la plaza de Casabindo, en medio del bullicio de voces, gritos y estruendo de bombas de la fiesta de San Santiago:

- ¿Lo han visto hoy? -volvió a decir el tuerto, gritando. De tan insistente y cerca no se dio cuenta de que estaba parado sobre las brasas. Tampoco los demás, que ni siquiera parecían verlo, y no le contestaron (p. 72).

El difunto manifiesta su enojo ${ }^{14}$ volcando de una patada la olla de la vendedora de choclos calientes:

Sin hallar respuesta, el hombre, furioso, golpeó el fuego con la punta de su bota y la olla se volcó.
- YYa te había advertido! -gritó la mujer-. ¡No hay que soportarla con tizones!
De un salto se incorporaron, salvando buena parte de lo que hervía y reacomodaron fuego y perol.
El sol atravesó las nubes en ese momento y el hombre se retiró, sin proyectar sombra (p. 73).

Según las creencias, los que fallecían de forma violenta podían quedarse más tiempo entre los vivos y asustar a las personas a lo largo de los caminos (Salvucci, 2016, p. 302). Varias señales manifiestan su presencia como un suceso especial, entre los que solían ocurrir en la fiesta de Santiago. Algunos lo ven, al hombre o a su caballo, los oyen o dicen que los han visto otros, es decir que se suceden las versiones, de boca en boca (pp. 117-118):

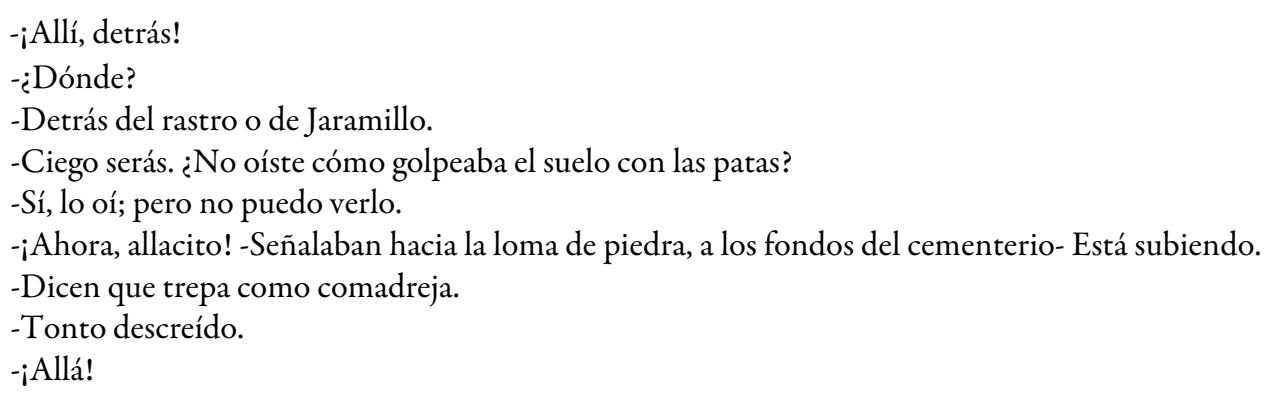

La profunda conexión entre víctima y victimario se refuerza paulatinamente, incluso caracterizándolos como dobles uno de otro o como un solo hombre:

Porque, como un relámpago, justamente en el momento en que, con toda la fuerza de su brazo, de su cintura, de sus pies firmemente posados en los estribos había arrojado la lanza a la cara del otro, se dio cuenta de que esa cara era como su propia cara, que él estaba mirando por los ojos del otro, que era su pelo el que crecía en aquella frente, que sentía la lengua seca del otro en su propia boca. Y ambos alaridos fueron como uno solo. Pero pasó. Después recién comprendió, cuando ya tampoco él era un hombre entero (121).

En una primera lectura, vinculamos esta asimilación de ambos hombres con la equivalencia, en cuanto a valía, de los adversarios en la epopeya antigua. Pero también aparecen en la novela fugaces conversaciones que indican una relación de hermanos, por las referencias a dos sobrinos criados bajo la tutela de Gonzalo Dies y de la niña Gertrudes, cuando de uno de ellos comentan que aprendía coplas de memoria y que "luego se hizo matar":

Y Genovevo agregó:

-Ése, al que luego mataron en Quera, de un lanzazo en un ojo. El otro muchacho se había ido mucho antes. Era menos apegado y, como le gustaba la milicia, desde temprano se enganchó como soldado (p. 115). 
Es decir que la posible relación de hermanos se muestra en algunas informaciones proporcionadas en el relato. Pero nuestra lectura quiere subrayar las particularidades de este texto literario, que parece haber procurado el efecto de que ambos personajes sean un solo hombre, y en un nivel más amplio de significación, que víctima y victimario están unidos por un lazo indisoluble y representan dos dimensiones del mismo ser humano.

También corroboran este vínculo los momentos en que la anciana los confunde. El tuerto, en busca del mayor López, va a hablar con una anciana, la madre, de la cual se infiere que es también la suya. Esta suerte de nékyia, puesto que acontece una comunicación entre uno de los muertos y la madre, viva aún, se da en sentido inverso a la de Odiseo, ya que éste era el hombre que, sin haber fallecido, se comunicaba con su madre por medio de un rito propiciatorio. Aunque se asemeja a la aparición de Patroclo a Aquiles en el sueño, no se presenta así en la novela, sino como una charla con una anciana que ya parece estar entre la vida y la muerte.

La madre de Odiseo podía contarle lo ya acontecido y también revelarle misterios escatológicos; en la novela, dos veces, una al principio (p. 15) y otra casi al final de la escena (p. 21), se oye una voz que invoca "Madre", sin que el lector pueda tener la certeza de quién lo dice, aunque parece ser la voz del tuerto que está llamando para entrar a averiguar por Doroteo: "-Madre -dijo una voz en la oscuridad, apagada también, y confusa, como alzada de un sueño, de una agonía o de una borrachera” (p. 15).

Además de tener poca movilidad y dificultades para hablar por la avanzada e imprecisa edad, ella tiene la facultad de la adivinación: la madre pudo presentir la llegada del "forastero" y saber lo que estaba ocurriendo por verlo en la piedralumbre: “-Venís huyendo, forastero: huís de tu ojo vacío pero tu ojo grita. Lo he visto en la piedralumbre. Ahí está todo. Y ahí te’i visto, montado en esa mula cagona (p. 21)”.

Esta última afirmación de la anciana anticipa la unión de los dos hombres, porque quien marchaba a Casabindo llevando a su mujer montada en una mula era el mayor López; en cambio, el tuerto se desplazaba con su caballo.

En el primer encuentro, el hombre le pregunta tres veces por el paradero de Doroteo y ella le da tres respuestas diferentes, es decir que elude darle precisiones. En principio, le dice que está muerto, por lo que se reflejaría en espejo con quien le está preguntando; luego señala el paso por Abra Pampa, donde habrían estado ambos hombres, pero finalmente le informa que está en el rodeo de los toritos de la Virgen, que es típico de la fiesta en Casabindo, ${ }^{15}$ lugar al que, en definitiva, los conducirá el destino.

Así como la voz de Anticlea no puede ser oída antes de beber ritualmente la sangre, la voz de la madre de Doroteo es difícil de comprender para el visitante, cuya voz también es confusa. Las razones de este primer desentendimiento pueden ser varias: por una parte, ha pasado tanto tiempo que no la reconoce, así como la anciana no reconoce a su hijo; por otra, ella está entre los vivos y el visitante es el ánima de un muerto, aunque la forma misteriosa de las apariciones posteriores de la anciana podría sugerir que ambos están en la misma condición.

Más adelante, confirmando lo que dicen las creencias sobre la ligazón de víctima y victimario, en dos oportunidades las palabras de la vieja unen, (con)funden al muerto (el tuerto) y al asesino, el mayor. En ambas ocasiones, al acercarse, el tuerto la ve, por un momento, como una mujer joven con cabellos negros y brillantes. En la primera, cuando le dirige la palabra vuelve a verla como anciana:

-Madre, ¿qué me querés?

Notó al hablar que su rejuvenecimiento fue sólo como una idea. La vieja fue achicándose y ahora estiraba sus manos pidiéndole algo. Él avanzó un paso más, echó mano al ala del sombrero y escuchó otro ruido de piedras esparcidas a un costado, enseguida el sonar de patas de caballo detrás de las pircas. Miró hacia allí, no vio nada y volvió la mirada a la vieja, que dijo: -Ahí stá. De nuevo no lo apercibiste (p. 48).

La reunión acontece en el camposanto y parece que los dos hombres están merodeando por el lugar apartado, cuando en el pueblo está comenzando la fiesta. Y más adelante: 
El tuerto creyó escuchar como que unas piedras se desmoronaban, aprestado miró hacia el lugar y sólo vio a la mujer de trenzas negras.

-Señora -dijo, descubriéndose. La mujer muy pronto se hizo vieja, estiró las manos hacia el hombre y dijo:

¡¡Doroteo, hijo!

-Madre, ¿qué me querés? -dijo el hombre, sin saber por qué (p. 69).

No solamente se unen los dos en uno solo desde la mirada de la anciana, asimismo esta escena refigura la comunicación de Odiseo con su madre. En primer lugar, porque, en la novela, también en este encuentro la mujer estira las manos hacia el hijo, aunque no lo toca, como en un espejo invertido con Odisea, donde es el hijo el que alarga, por tres veces, sus brazos para tomarla entre ellos.

Luego, el hombre, después de que su madre lo ha llamado, se descubre de pronto "de hinojos en el cementerio" y el narrador nos cuenta que "el hombre observó cómo la vieja Santusa, apoyada en su bastón de chaguaral, se alejaba otra vez camino de la iglesia” (p. 69). Y allí el narrador, además de ubicarnos en un ámbito propicio para la nékyia como es el cementerio en este contexto, vuelve a llevarnos al mundo homérico, usando imágenes descriptivas que evocan a aquellas de las almas que se van volando como un sueño: "Tardó una eternidad en andar la distancia, pero siguió sus pasos, viéndola ir, como un recuerdo que no atrapamos, que se nos escapa" (p.69).

La mujer joven de cabello negro bien puede estar solo en el recuerdo del hijo, como dice en un pasaje del episodio del regreso al pueblo natal por la muerte de su padre:

Madre, mamá, madrecita

Él la llamó, pero de su madre, mujer de Casabindo que había servido durante un tiempo en la finca de Yavi, apenas si tenía memoria de sus ojos y de unas trenzas negras, puesto que lo habían alejado de ella, aun antes de terminar de amamantarse (p. 84).

Tres veces a lo largo de la novela acontecen estos diálogos con la madre antes de que se produzca la confluencia decisiva del tuerto y el mayor.

El primer episodio es el de consulta a la madre por Doroteo. En Odisea la madre suma al conocimiento de la condición de los muertos algunas noticias de la vida de los familiares en Ítaca, anticipándose al regreso y reconocimiento del héroe. El protagonista de la novela habla con la anciana para averiguar su destino: al saber dónde está el otro podrá hallarlo y encontrarse a sí mismo, podrá completarse con la muerte del otro; de esa reunión dependerá el descanso del alma, la propia y la del victimario.

Sumadas a la anterior las otras dos escenas de diálogo con la anciana, los momentos en que se habla de la relación de vivos y muertos, y la escena final de la novela, se puede afirmar que el epígrafe no solo sella un pacto de lectura, sino que también las connotaciones que acumula, en el diálogo entre textos, están diseminadas a lo largo de la novela y multiplican los efectos de sentido.

En Fuego en Casabindo es necesario el encuentro con el otro para morir definitivamente. La madre y el hombre hablan sobre el otro a quien busca y que lo complementa. Sólo concluye su trayectoria al hallarlo, se realiza la conjunción de ambos y definitivamente es un cadáver de muchos días y un alma que tendrá su descanso definitivo. ${ }^{16}$ Es decir que el otro, que es su doble, es necesario para completarse como hombre al morir.

$\mathrm{Al}$ integrarse varias interpretaciones por la indeterminación del texto literario, más allá de constatar una relación familiar, también se puede considerar que esta novela propone un hermanamiento y puesta en pie de igualdad de los combatientes enfrentados desde un punto de vista de los intereses y actitudes humanas en un entorno bélico.

Como parte de los fragmentos de historias anteriores y paralelas que se narran en la novela, tenemos un regreso del que será muerto en Quera, junto con el tío Gonzalo, a su tierra de origen por la muerte de su padre. Es un hecho ocurrido en su juventud, antes de la guerra. 
Una vez muerto, al finalizar el enfrentamiento de Quera, se desarrolla el viaje que atraviesa el texto novelesco: el itinerario del alma errante hasta el reencuentro en Casabindo. Es una "pequeña Odisea" la que traza el personaje hasta su reconocimiento.

El narrador menciona y caracteriza brevemente los sitios de la puna por donde fue pasando y aclara:

Y todo eso que le llevó treinta años de la vida, ahora volvía a recorrer de un solo golpe, devuelto a la semilla, montado en el caballo que debía ayudarle en la búsqueda para salvar su propia condición de independencia (pp. 85-86).

Así el jinete llega a la que había sido su casa, ya arruinada, donde fue que lo recogieron "tuerto, desfallecido y frío" pero es donde estuvo, como nunca, "más cerca de su alma". Con lo cual podemos entender que en el regreso al origen encuentra su anagnórisis. De allí en más, sólo le restaba llegar a Casabindo: "El caballo pareció comprenderlo y descansó distanciado de los demás, antes de emprender el camino restante a Casabindo" (p. 86).

Hemos comprobado cómo, desde la sucesión de retazos de historias que atañen a lo individual de algunos personajes como a los acontecimientos colectivos que encarnan, se ha desplegado todo un regreso, viviente, al mundo del pasado de este pueblo que "andaba a gatas por esta tierra seca y dura y que antes había sido capaz de crear más de dos mil cantares” (p. 21).

Sabemos que las epopeyas antiguas surgían de la reunión de los relatos de episodios heroicos conservados por la memoria de los rapsodas, que luego el aedo componía en su propio poema en el momento de la actuación. De modo similar, Fuego en Casabindo obtuvo su materia ficcional de los relatos y cantares conservados en la memoria oral del pueblo jujeño. ${ }^{17}$

En síntesis, el itinerario del alma ${ }^{18}$ después de la muerte conecta los diferentes planos que componen la novela: a) constituye la materia narrativa (los relatos orales y cantares son los materiales pretextuales), b) se imbrica en la estructura por medio de la matriz narrativa que la atraviesa de principio a fin y la sustenta aunque la forma de narrarla apele a la fragmentación espacial y temporal-, c) la impregna de sentido, al rescatar las luchas del pasado y las creencias que persisten en el pueblo, y reunirlas con el propósito de sacar a la luz y comprender las raíces históricas de las condiciones de vida actuales.

El tono luctuoso vinculado a las cuestiones del más allá también se aprecia en esa suerte de elegía por el pasado indígena, en la contraposición de "antes" y "ahora” con que se inicia la novela. De esos pueblos que tuvieron su momento de plenitud, y que luego fueron derrotados, esta novela no construyó una epopeya, sino que expuso lo que todavía permanecía -aunque fuera de manera fragmentaria en cantares y relatos orales- de la cultura originaria y de sus luchas históricas.

\section{REFERENCIAS}

Alesso, M. (Inéd.). Homero. Odisea. (trad. y notas). Recuperado de http://www.academia.edu/ Bérard, V. (Ed.). (1947). L’Odyssée; poésie homérique, 4 Vol. Paris: Les Belles Lettres.

Brunel, P. y Chevrel, I. (1994). Compendio de literatura comparada. México: Siglo XXI.

Calvo, J. L. (Ed.). (2001). Homero. Odisea. Madrid: Cátedra.

Gilio, M. E. (1975). Héctor Tizón. Mateando con el diablo y los muertos. Crisis, 21, 40-47.

Homero. (1957). Obras completas. Trad. Luis Segalá y Estalella. Buenos Aires: El Ateneo.

Krmpotic, C. S. y Vargas, A. N. (2018). El día de los muertos y el cuidado del espíritu en el noroeste argentino. Culturahombre-sociedad, 28(2), 227-247. doi: https://dx.doi.org/10.7770/0719-2789.2018.cuhso.06.a08

Massei, A. P. (1998). Héctor Tizón. Una escritura desde el margen. Córdoba: Alción.

Murray, A. T. (Ed.). (1953) Homer. The Odyssey, 2 vol. Cambridge, MA.: Harvard University Press; London: William Heinemann.

Pabón, J. M. (Trad.) (2000). Homero. Odisea. Madrid: Gredos. 
Pérez, F. J. (Ed.). (2012). Homero. Ilíada. Edición bilingüe. Madrid: Abada.

Salvucci, D. (2016). Convidar a las almas, convidar a la Tierra. Lógicas rituales y categorías de relación entre seres en la Argentina andina. Bulletin de l'Institut français d'études andines, 45 (2), 289-305. doi: https://doi.org/10.40 00/bifea.7995

Terrón de Bellomo, H. (2007). El saber de los relatos. Córdoba: Ferreyra Editor.

Tizón, H. (1982). El cantar del profeta y el bandido. Buenos Aires: Centro Editor de América Latina. (Primera edición publicada en 1972).

Tizón, H. (2000). Fuego en Casabindo. Buenos Aires: Alfaguara. (Primera edición publicada en 1969).

Tizón, H. (2003). Sota de bastos, caballo de espadas. Buenos Aires: Alfaguara. (Primera edición publicada en 1975).

\section{Notas}

1 La investigación plasmada en este artículo es parte de la tesis Mitos y motivos griegos en la narrativa de Héctor Tizón, escrita en el marco del Doctorado en Letras de la Facultad de Humanidades de la Universidad Nacional del Nordeste.

2 Od. 11.218. Las citas de Odisea remiten a la edición de A. T. Murray (1953).

3 Héctor Tizón (Rosario de la Frontera, Salta, 1929 - San Salvador de Jujuy, 2012) publicó en 1960 su primer libro, los cuentos de $A$ un costado de los rieles, y en 2012, el último, Memorial de la Puna.

4 Fuego en Casabindo (2000, p. 42).

5 Hemos constatado la presencia de esta edición en la biblioteca personal del escritor en San Salvador de Jujuy.

6 Transcribimos textualmente la cita, con la referencia al pasaje de Odisea tal como está indicado en el epígrafe de la novela.

7 Cf. Marta Alesso (inéd.), en una de las notas a su traducción de Odisea: "Hay una aparente falta de la cohesión y existe una yuxtaposición de elementos procedentes de muy dispares fuentes mitológicas y religiosas, lo cual hace suponer que el canto esté compuesto de capas de material cuya composición corresponde a épocas distantes" (Nota 1 al canto 11).

8 Versión de Segalá (1957): “y el alma se va volando, como un sueño”. Calvo (2001) traduce: "y el alma anda revoloteando como un sueño.” Pabón (2006): “sólo el alma, escapando a manera de sueño, revuela por un lado y por otro.” Alesso (inéd.): "y el alma como un sueño revoloteando se aleja." Bérard (1946) "l’ombre prend sa volée et s'enfuit comme un songe...”. Murray (1953) "and the spirit, like a dream, flits away, and hovers to and fro."

9 Las versiones en español son propias.

10 Las citas de Ilíada remiten a la edición de F. J. Pérez (2012).

11 Terrón de Bellomo (2007, pp. 47-48) explicó que los conceptos esenciales estaban contenidos en los relatos orales y que la evangelización pretendió combatir la idolatría suprimiéndolos; pero el hombre andino no necesitaba sólo de esos relatos "para conservar su cultura: su entorno estaba cargado de significados que él sabía interpretar. Así, por ejemplo: cumbres, mojones, encrucijadas de caminos, confluencias de ríos, no eran sólo señales viales sino el espacio donde se podía relacionar con sus antepasados, con los vecinos, con los dioses. Ese concepto de mundo es el que impidió que se anulara la memoria."

12 Referencia a que el alma debía despedirse del mundo dentro del tiempo ritual y que era necesario que tuviera compañía en ese tránsito. En este caso, vemos reflejado, en una humanización del caballo, el temor de que, si no se daba el reencuentro con el asesino, podría ser elegido para acompañar a su jinete.

13 Cf. La entrevista a Héctor Tizón publicada por Crisis $\mathrm{N}^{\circ} 21$, enero de 1975, sobre las creencias y ritos sobre la muerte y los muertos, la particular y diferente concepción de las culturas autóctonas, que, como ya expusimos, no separan taxativamente las partes del mundo, sino que sus muertos están presentes entre los vivos, los visitan y comparten fiestas. Especialmente en el día de los muertos, los deudos van a visitarlos y beben con ellos junto a sus tumbas. No es angustiante ni lúgubre ni sombrío como para otras formas de pensar, cristianas, de una buena parte de la sociedad "blanca".

14 En Krmpotic y Vargas (2018, p. 241) los informantes describen varias manifestaciones con las cuales se dan cuenta de la presencia de los difuntos y de si están contentos o enojados; por ejemplo, si las velas se apagan o si se queman las coronas.

15 La fiesta que se desarrolla en la novela es la del santo Santiago (25 de julio), aunque Casabindo es famoso por la fiesta de la Virgen (15 de agosto).

16 "Y así los lloraron e hicieron las honras de ambos" (p. 125).

17 Héctor Tizón, en el prólogo a la reedición, denominado “Treinta años después”, dice de esta novela que sus "entresijos permanecen aún tan oscuros como lo fueron cuando de varias voces a la vez escuché aquello que luego sirvió para su historia" (p. 9).

18 Aunque solamente en Fuego en Casabindo el motivo cobra centralidad, la separación del alma después de la muerte y las referencias al mundo de los muertos están presentes también en las otras dos novelas de ámbito jujeño. Cfr. El cantar del profeta y el bandido (1982, p. 87) y Sota de bastos, caballo de espadas (2003, pp. 104 y 105). 